\title{
AS RAZÕES TRIGONOMÉTRICAS NO TRIÂNGULO RETÂNGULO: RELATO DE UMA ATIVIDADE INVESTIGATIVA NOS CURSOS DE ENGENHARIA
}

Érika J. Maia-Afonso - prof.erika@ feitep.edu.br

Faculdade de Engenharia e Inovação Técnico Profissional, FEITEP Av. Paranavaí, 1164, Pq. Industrial Bandeirantes

87070130 - Maringá - Paraná

Lucas V. Dias - lucasv.dias@ outlook.com

Gabrieli A. Vicentini-gabrielivicentini95@gmail.com

Sandra M. Dias - sandradiassml@gmail.com

Resumo: Os currículos dos cursos de Engenharia devem dar condições a seus egressos para adquirirem competências e habilidades ligadas a matemática e suas aplicações. Porém, pesquisas realizadas com graduandos de cursos de Engenharia em todo Brasil, apontam para a defasagem e dificuldade que estes acadêmicos apresentam nas disciplinas específicas do curso que envolvem a matemática básica. Diante deste cenário, seguindo as orientações $e$ encaminhamentos da Investigação Matemática, neste artigo, apresentamos o relato do desenvolvimento de uma atividade investigativa que teve por objetivo verificar como os acadêmicos dos cursos de Engenharia identificam (constroem) as relações trigonométricas no triângulo. Para tanto, participaram da pesquisa 25 acadêmicos matriculados no $1^{o}$ semestre dos cursos de Engenharia de uma IES. Os resultados revelaram que ao compreenderem/construírem as relações existentes entre o triângulo retângulo e os ângulos notáveis durante a realização da atividade, os acadêmicos puderam desenvolver o intuito de investigadores. Além disso, a atividade ajudou a aguçar a curiosidade nesses acadêmicos que se mostraram interessados e motivados durante todo o processo. Concluímos que a Investigação Matemática pode se constituir como um auxílio ao professor para o processo de ensino-aprendizagem da matemática básica no que diz respeito a ressignificação de conceitos.

Palavras-chave: Educação em Engenharia. Matemática básica. Trigonometria. Investigação Matemática.

\section{INTRODUÇÃO}

Ao consultar o parecer do Ministério da Educação na Resolução CNE/CES no 2 de 24 de abril de 2019, que institui as Diretrizes Curriculares Nacionais dos Cursos de Engenharia, é possível observar que os currículos desses cursos devem dar condições a seus egressos para adquirirem competências e habilidades ao decorrer de sua graduação. Sendo algumas 
relacionadas a matemática e suas aplicações, tais como: aplicar conhecimentos matemáticos, científicos, tecnológicos e instrumentais à engenharia; identificar, formular e conceber soluções desejáveis a problemas de engenharia; desenvolver e/ou utilizar novas ferramentas e técnicas, atualizando-se em relação aos avanços da ciência, da tecnologia e aos desafios da inovação; comunicar-se eficientemente nas formas escrita, oral e gráfica (BRASIL, 2019).

Segundo consta no parecer CNE/CES n 2 de 24 de abril de 2019, as disciplinas que contemplam a matemática básica são ministradas ao decorrer dos primeiros semestres da graduação em Engenharia. A carga horária destas disciplinas, conforme a resolução de 2019, fica a encargo do planejamento pedagógico da instituição, mas vale ressaltar, que no parecer anterior do Ministério da Educação (CNE/CES 1.362/2001) as denominadas disciplinas de núcleo de conteúdo básicos totalizavam cerca de $30 \%$ da carga horária total do curso.

Mesmo diante da importância que a matemática assume dentro da graduação em Engenharia, pesquisas realizadas com graduandos de cursos de Engenharia em todo Brasil, apontam para a defasagem e dificuldade que estes acadêmicos apresentam em disciplinas que envolvem a matemática básica (MENESTRINA; MORAIS, 2011; GODOY; ALMEIDA, 2017; VILLELA; CONDÉ; NUNES, 2018). Segundo Ferreira e Brumatti (2009, p. 51) "[...] as disciplinas de matemática costumam ser responsáveis por um alto grau de apreensão nos estudantes, desencadeando alto índice de reprovações e até evasões do curso", podendo tornarse um grande desafio para os acadêmicos que optam por uma graduação em Engenharia.

Neste sentido, a pesquisa de Maia, Rosa e Afonso (2018) que buscava investigar como os acadêmicos ingressantes nos cursos de Engenharia resolvem problemas matemáticos e como concebem os conceitos matemáticos investigados, utilizou como instrumento de coleta de dados um questionário informativo que foi aplicado para 207 acadêmicos e que abordava os conceitos de álgebra, trigonometria e geometria. Os resultados evidenciaram que os investigados, de modo geral, demonstraram ter esquecido os conceitos básicos da matemática que foram aprendidos no ensino básico, e apresentaram dificuldades na interpretação de problemas matemáticos. Ao questionarem os acadêmicos sobre quais os conteúdos de maior dificuldade dentre aqueles que foram propostos no questionário, verificaram que primeiramente foi citado álgebra com 41,18\%, e em seguida, a trigonometria com 32,67\%. Neste sentido, os autores apontaram como recomendação de pesquisas futuras a busca por meios pedagógicos que possam auxiliar esse processo de ensino-aprendizagem.

Dessa forma, tendo por base a necessidade de estudos que busquem promover alternativas que forneçam condições para que estas dificuldades sejam sanadas e afim de contribuir para este processo, esta pesquisa foi planejada e aplicada seguindo as orientações e encaminhamentos da Investigação Matemática, compreendida como uma tendência para o ensino da Matemática, e tem por objetivo apresentar um relato de uma experiência que buscou investigar como os acadêmicos dos cursos de Engenharia identificam (constroem) as relações trigonométricas do triângulo a partir de uma atividade investigativa.

\section{INVESTIGAÇÃO MATEMÁTICA}

A Investigação Matemática busca evidenciar as possíveis relações existentes entre os objetos matemáticos, sendo estes conhecidos ou desconhecidos, procurando identificar suas respectivas características e propriedades. Nela o investigador constrói relações e hipóteses que podem ser testadas e analisadas (conjecturas), a fim de solucionar o proposto pela pesquisa, ou identificar novas descobertas (PONTE; BROCARDO; OLIVEIRA, 2009).

Ponte, Brocardo e Oliveira (2009), expõe que, ao se propor uma tarefa de investigação, espera-se que os alunos possam, de uma maneira mais ou menos consistente, utilizar os vários 
processos que caracterizam a atividade investigativa em Matemática. Sendo assim, para que o professor possa conduzir o ensino de matemática, privilegiando uma aprendizagem investigativa, é necessário que os alunos realizem os quatro momentos que compõe a atividade investigativa. Esses momentos foram apresentados no Quadro 1.

Quadro 1 - Momentos da realização de uma investigação

\begin{tabular}{|l|l|}
\hline $\begin{array}{l}\text { Exploração e formulação de } \\
\text { questões }\end{array}$ & $\begin{array}{l}\text { Reconhecer uma situação problemática; explorar a situação problemática; } \\
\text { formular questões }\end{array}$ \\
\hline Conjecturas & $\begin{array}{l}\text { Organizar dados; formular conjecturas (e fazer afirmações sobre uma } \\
\text { conjectura) }\end{array}$ \\
\hline Testes e reformulação & Realizar testes; refinar conjecturas \\
\hline Justificação e avaliação & Justificar uma conjectura; avaliar o raciocínio ou o resultado do raciocínio \\
\hline
\end{tabular}

Fonte: Ponte, Brocardo e Oliveria (2009, p. 21).

Segundo Ponte, Brocardo e Oliveira (2009), o primeiro momento da atividade investigativa envolve o reconhecimento da situação problema, a sua exploração preliminar quanto aos seus aspectos e desenvolturas, e a formulação de questões que possam contribuir para encontrar a solução do problema proposto. No segundo momento, leva-se em conta o processo de formulação de conjecturas por parte do solucionador, que segundo Ribeiro (2019) consiste na ação de opinar, supor, deduzir e criar hipóteses de um determinado assunto sem realizar sua comprovação real. Além disso, para gerar essas conjecturas é preciso que o investigador organize os dados obtidos da exploração da situação problema afim de verificar o que pode ser útil de imediato para iniciar o procedimento de solução. Em seguida, com as hipóteses e suposições estabelecidas, ocorre o terceiro momento, que por sua vez, visa a realização de testes e comprovações das conjecturas previamente elaboradas. A partir desses testes, ocorre o refinamento das conjecturas. Por fim, temos o quarto e último momento, que diz respeito as considerações que são retiradas do trabalho, levando em conta a argumentação, à demonstração e avaliação do que foi realizado (PONTE; BROCARDO; OLIVEIRA, 2009).

De modo geral, a principal característica da investigação matematica, está na elaboração das ideias e hipóteses aqui caracterizadas como conjecturas, que serão testadas e demonstradas pelo investigador. Nesta tendência da Educação Matemática, o acadêmico não é somente exposto a matemática, mas é chamado a agir como um matemático, realizando suas formulações, provando-as e discutindo estas posteriormente com seus colegas e professor. Diante deste cenário, a interpretação por parte do aluno se torna ferramenta fundamental do pensamento já que ao tentar resolver um problema matemático pode-se fazer outras descobertas no percurso sobre o conteúdo que podem ser mais importantes que o objetivo original para o qual o problema foi formulado (PONTE; BROCARDO; OLIVEIRA, 2009).

No que diz respeito ao papel do professor durante a realização de uma atividade investigativa, Ponte, Brocardo e Oliveira (2009) afirmaram que este deverá desenvolver três fases. Na primeira fase é necessário apresentar a atividade com uma introdução oral aos alunos pois mesmo com a entrega de material escrito, é imprescindível e indispensável, uma apresentação oral, a fim de perceber se os alunos compreenderam a tarefa, bem como quais foram as suas reações perante ela. Esse momento inicial é denominado pelos autores de arranque da aula, em que o aluno deve sentir-se desafiado e motivado a realizar a atividade investigativa proposta. Já na segunda fase, o professor deverá separar a turma em grupos menores a fim de gerar uma interação entre os alunos. Por fim na terceira fase, deve-se realizar uma discussão dos resultados entre os participantes (socialização), com o intuito de verificar quais são as conclusões obtidas da atividade investigativa que foi desenvolvida. 
Nesta pesquisa, em específico, quanto as competências e/ou habilidades que o trabalho investigativo se propõe a desenvolver, destacamos que esperávamos que o acadêmico fosse capaz de usar conhecimentos matemáticos na resolução da tarefa proposta.

\section{METODOLOGIA}

Este artigo apresenta uma pesquisa de natureza qualitativa que de acordo com Neves (2015) não possui foco na quantidade de dados coletados, mais sim na análise, descrição e compreensão do fenômeno pesquisado afim de compreender seu significado, uma vez que seu objetivo é apresentar um relato de uma experiência desenvolvida.

Quanto ao objetivo da pesquisa, segundo Gil (2002), foi caracterizada como exploratória, pois busca maior familiaridade com o problema investigado, procurando esclarecê-lo. Quanto as técnicas de coleta de dados, utilizou-se a observação que de acordo com Ferreira, Torrecilha e Machado (2012) é indicada para analisar o comportamento e os acontecimentos no momento de sua ocorrência, sem a intervenção de documento ou pessoas, ajudando o pesquisador com detalhes e o deixando em um cenário abrangente. Também foram realizadas gravações de áudios durante a atividade investigativa para obter transcrições que consigam assegurar fidelidade às informações coletadas. Além disso, os registros escritos dos alunos foram coletados por meio do preenchimento de 4 fichas, elaboradas previamente pelos pesquisadores.

Para seleção do conteúdo que seria trabalhado na atividade investigativa, primeiramente, foi realizada uma busca na ementa dos cursos de Engenharias de uma IES privada, localizada no norte do Paraná, e foi constatado que a trigonometria está fortemente presente nas disciplinas de núcleo comum relacionadas ao cálculo, e que devem ser cursadas pelo acadêmico até o $4^{\circ}$ semestre da graduação. Diante dessa análise dos conteúdos apresentados nas diferentes disciplinas, foi adotado como tema da investigação as "Noções básicas sobre as razões trigonométricas no triângulo retângulo", conteúdo inicialmente apresentado durante o $9^{\circ}$ ano do Ensino Fundamental e que é aprofundado durante as disciplinas de núcleo comum.

\subsection{Descrição Da Implementação}

Participaram da pesquisa 25 acadêmicos matriculados no $1^{\circ}$ semestre dos cursos de Engenharia Civil, Engenharia de Computação, Engenharia Elétrica, Engenharia Mecânica e Engenharia Química de uma IES selecionada. Vale ressaltar, que quando o convite foi feito aos participantes, não foi mencionado qual conteúdo seria abordado durante a realização da atividade, pois isso poderia influenciar os acadêmicos na execução de seus procedimentos, portanto foi informado que se tratava apenas de um assunto relacionado a matemática básica.

A atividade foi realizada no primeiro semestre de 2018, em um horário extracurricular (sábado à tarde), para que pudesse atender as necessidades dos alunos que durante os dias de semana trabalhavam. Foi uma atividade realizada paralelamente as disciplinas do curso, e teve duração de 4 horas aulas.

A atividade foi dividia em três momentos, respeitando os princípios da Investigação Matemática. Inicialmente, para a execução do primeiro momento houve a apresentação oral da atividade para todos os acadêmicos por parte dos pesquisadores, que realizaram perguntas como: "O que são triângulos?", "O que caracteriza um triangulo?", "Quais os tipos de triângulos?", "O que é a altura de um triangulo?", buscando promover o momento de arranque inicial da aula e provocar o interesse pela atividade que seria desenvolvida por eles, conforme é sugerido por Ponte, Oliveira e Brocardo (2009). As respostas que surgiram foram anotadas pelos pesquisadores no quadro e discutidas coletivamente. 
Em seguida, fazendo referência ao segundo momento descrito por Ponte, Brocardo e Oliveira (2009), solicitamos aos alunos que se dividissem, em no máximo, 5 grupos (deixamos que eles decidissem como fariam essa divisão), e entregamos as atividades que deveriam ser realizadas. Os grupos foram identificados como G1, G2, G3, G4 e G5, e cada um deles recebeu: um gravador, 4 fichas (a primeira referente a construção de triângulos equiláteros, a segunda referente a construção de triângulos escalenos, a terceira referente a construção de triângulos isósceles, e a quarta referente a generalização das características dos triângulos) e folhas de sulfites para que pudessem realizar as construções. Além disso, solicitamos que os participantes trouxessem compasso, régua e transferidor. Durante o processo de resolução das fichas, os gravadores foram deixados sobre as carteiras dos acadêmicos para registrar as conjecturas que cada grupo iria propor durante a realização da atividade.

Quando os grupos terminaram de preencher as fichas, foi realizada a discussão dos resultados obtidos por estes coletivamente, conforme é indicado no terceiro momento proposto por Ponte, Oliveira e Brocardo (2009), e foram estabelecidas as possíveis conclusões que poderiam ser tomadas referentes as atividades propostas pelas fichas de acordo com as informações apresentadas.

\section{DISCUSSÕES E RESULTADOS}

A primeira ficha entregue aos acadêmicos abordava o conceito de triângulo equilátero, e trazia como orientação "Construa alguns triângulos equiláteros. Em seguida, com os dados desses triângulos, complete o quadro a seguir":

\begin{tabular}{|c|c|c|c|c|c|c|c|c|c|c|c|c|c|}
\hline \multirow{2}{*}{\multicolumn{5}{|c|}{ Medidas }} & \multicolumn{9}{|c|}{ Relações eutre os lados } \\
\hline & & & & & \multicolumn{3}{|c|}{$\hat{A}$} & \multicolumn{3}{|c|}{$\widehat{\mathrm{B}}$} & \multicolumn{3}{|c|}{$\hat{\mathrm{C}}$} \\
\hline $\begin{array}{l}\text { Lado } \\
(\mathrm{cm})\end{array}$ & $\begin{array}{c}\text { Altura } \\
(\mathrm{cm})\end{array}$ & $\begin{array}{c}\hat{A} \\
\text { (graus) }\end{array}$ & $\begin{array}{c}\widehat{\mathrm{B}} \\
\text { (graus) }\end{array}$ & $\begin{array}{c}\hat{\mathrm{C}} \\
\text { (graus) }\end{array}$ & $\frac{\mathrm{CO}}{\mathrm{HIP}}$ & $\frac{\mathrm{CA}}{\mathrm{HIP}}$ & $\frac{\mathrm{CO}}{\mathrm{CA}}$ & $\frac{\mathrm{CO}}{\mathrm{HIP}}$ & $\frac{\mathrm{CA}}{\mathrm{HIP}}$ & $\frac{\mathrm{CO}}{\mathrm{CA}}$ & $\frac{\mathrm{CO}}{\mathrm{HIP}}$ & $\frac{\mathrm{CA}}{\mathrm{HIP}}$ & $\frac{\mathrm{CO}}{\mathrm{CA}}$ \\
\hline
\end{tabular}

Após preencherem a ficha, os alunos deveriam responder as seguintes perguntas: "O que vocês concluíram desta atividade?", e "Que características vocês encontraram para o triângulo equilátero?".

Logo após a entrega dessa primeira ficha, observamos que os acadêmicos não haviam participado durante sua trajetória escolar de atividades com características investigativas e que essa se tratava de sua primeira experiência. Sendo assim, a inserção desses alunos em uma atividade investigativa constitui-se como a principal dificuldade dos pesquisadores, uma vez que estes acadêmicos estavam acostumados com enunciados de atividades que já lhes forneciam detalhadamente o que deveria ser realizado, o que por sua vez, não é uma característica da Investigação Matemática. A transcrição apresentada a seguir, mostra um diálogo entre os acadêmicos do G1 para compreenderem o que deveria ser feito na atividade:

"A: Isso aqui é a atividade? (referindo-se à primeira ficha) Ah, acho que a primeira folha é a atividade e a segunda é a resposta.

B: primeiro é pra fazer um triângulo equilátero!

D: equilátero?

B: É!

A: Mas qual é o exercício que eu não entendi até agora o que é pra fazer?

(um integrante do grupo leu o que estava escrito na ficha 1 para ser feito)

A: mas é pra fazer alguns?

B: é, vamos cada um construir um!"

Destacamos que essas discussões em uma atividade investigativa são comuns de ocorrer, pois conforme foi apontado por Ponte, Brocardo e Oliveira (2009), no contexto de ensino e aprendizagem, "investigar" significa trabalhar com questões que nos interpelem e que se apresentam no início de modo confuso, mas que procuramos clarificar e estudar de modo 
organizado. Além disso, é importante destacar que a interpretação da tarefa a ser realizada é um dos objetivos das aulas investigativas e espera-se que os alunos a realizem de maneira autônoma ou em conjunto com seus colegas (PONTE; BROCARDO; OLIVEIRA, 2009).

Buscando por essa interpretação e organização da tarefa, os grupos apresentaram discussões para determinar a quantidade de triângulos que deveriam ser construídos, uma vez que essa informação não foi fornecida pelo enunciado da atividade. Nesse sentido, foram elaboradas as primeiras conjecturas, como pode ser observado nas discussões apresentadas pelo G3:

"G: vamos fazer um triângulo equilátero todo mundo com medida de $4 \mathrm{~cm}$

M: eu acho que como vamos ter que construir mais de um triângulo, já que é construa alguns triângulos, cada um já pode construir um

$G$ : mas vai ter tudo resposta diferente?

A: é, mas eu acho que é pra gente comparar as repostas"

Após as discussões realizadas pelos grupos, verificamos que somente o G5 construiu um único triângulo, preenchendo somente uma linha da tabela, enquanto os outros grupos variaram as dimensões dos triângulos conforme desejavam, e construíram um triângulo por participante, obtendo uma visualização genérica de como os triângulos equiláteros se comportam quando se alteraram suas dimensões.

Uma dificuldade encontrada pelos acadêmicos durante o preenchimento da tabela estava relacionada ao fato de determinar a altura do triângulo equilátero. Ao traçar a altura no triângulo equilátero seria possível perceber a construção de dois triângulos retângulos, o que permitiria trabalhar com os valores de cateto oposto (CO), cateto adjacente (CA) e hipotenusa (hip) para cada ângulo solicitado. Diante dessa dificuldade constatada pelos pesquisadores, foi necessário intervir nos grupos para que os acadêmicos conseguissem explorar e formular conjecturas, testá-las e reformulá-las quando necessário. Um exemplo pode ser observado na transcrição do G4 que é apresentada a seguir, em que P representa um dos pesquisadores:

"P: está certo esse daqui?

C: qual professora? por quê?

P: em relação a esse seu ângulo Ầ você está me dizendo que ele tem cateto oposto para qual triângulo?

C: o triângulo inteiro professora (se referindo ao triângulo equilátero construído)

$P$ : entendi. Então vamos lá, todo triângulo tem CO $e$ CA?

E: $\operatorname{sim}$

$P$ : todo triângulo?

A: esse não, porque é tudo igual.

$B$ : ah professora, tá errado porque o triângulo tem que ser retângulo para ter $\mathrm{CO}$ e $\mathrm{CA}$

P: Então vocês não podem dizer que esse triângulo inteiro tem um cateto oposto, podem?

$C$ : não, porque ele não é retângulo. Por isso que a senhora deu a altura pra gente né?

P: isso, exatamente. Seu Cateto oposto agora é tudo isso aqui?

C: não, vamos ter que mudar os cálculos porque vai ser só a metade disso aí

A: o que tem que fazer então?

$C$ : esse triângulo inteiro não tem cateto oposto, por isso que a atividade pede pra gente calcular a altura porque daí agora nós temos um triângulo menor aqui

I: agora tem que levar em consideração só cada lado do triângulo

C: aí por exemplo, agora eu teria aqui um ângulo de $90^{\circ}$ e ali um de $60^{\circ}$ e agora o $\mathrm{CO}$ é 6,9 porque é a altura do triângulo. Ah, entendi... então agora não vamos mais enxergar o triângulo inteiro, só metade dele!"

As partes em negrito da transcrição foram destacadas por representarem o processo de elaboração de uma conjectura, seu teste e sua reformulação/refutação quando está não atende ao que foi solicitado pela atividade. Neste sentido, Ponte, Brocardo e Oliveira (2009, p. 10) apontaram que "as investigações matemáticas envolvem conceitos, procedimentos e representações matemáticas, mas o que mais fortemente as caracteriza é este estilo de conjectura-teste-demonstração".

Quando ocorreu a discussão nos grupos para concluírem a atividade, foi possível observar o papel investigativo assumido pelos acadêmicos, uma vez que segundo Ponte, Brocardo e 
Oliveira (2009, p. 23) na atividade investigativa "o aluno é chamado a agir como um matemático, não só na formulação de questões e conjecturas e na realização de provas e refutações, mas também na apresentação de resultados e na discussão e argumentação com os seus colegas e professor". Este fato pode ser representado pelo diálogo a seguir que foi realizado no $\mathrm{G} 2$ :

"S: O que você está fazendo?

T: um triângulo de $18 \mathrm{~cm}$ de lado, para ver como vai ficar os números nele, só por curiosidade, para ver como vai ficar as medidas

S: mas se você fizer um do tamanho da folha aqui, de $32 \mathrm{~cm}$, vai dar a mesma coisa

T: É? Eu não sei no que eu quero chegar e tô fazendo um monte de triângulo extra

S: não precisa fazer outro, vai dar tudo igual sempre os valores

B: sério?

S: claro, é o mesmo resultado sempre, independente do tamanho do seu triângulo, olha os que a gente fez

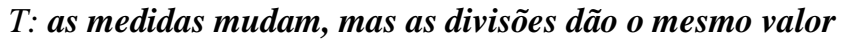

T: não precisa nem dividir

B: por quê?

S: olha aqui, as medidas são todas proporcionais porque é um triângulo equilátero."

Para finalizar a ficha 1, de modo geral, ao identificarem o que concluíram da atividade, os grupos apresentaram as seguintes respostas: "independente do tamanho do triângulo equilátero os valores de $\frac{C O}{H I P}, \frac{C A}{H I P}, \frac{C O}{C A}$ não mudam" e que "os valores dos ângulos são sempre iguais para o triângulo equilátero (correspondendo a $60^{\circ}$ )".

Para a resolução das outras fichas que foram propostas, os acadêmicos utilizaram como ideias iniciais as conjecturas que foram estabelecidas na realização da atividade anterior, o que segundo Ponte, Brocardo e Oliveira (2009), é habitual pois após o surgimento das primeiras conjecturas, a formulação de outras questões e conjecturas geralmente são realizadas por analogia.

A segunda ficha levava em consideração um triângulo escaleno, em específico um triângulo escaleno reto. De todos os grupos, apenas o G2 compreendeu como o triângulo poderia ser dimensionado e ao estabelecerem o ângulo reto, encontraram os ângulos de $30^{\circ} \mathrm{e}$ $60^{\circ}$ que completariam os ângulos internos do triângulo escaleno reto, como pode ser observado na Figura 1.

Figura 1 - Ficha 2 preenchida pelo grupo G2

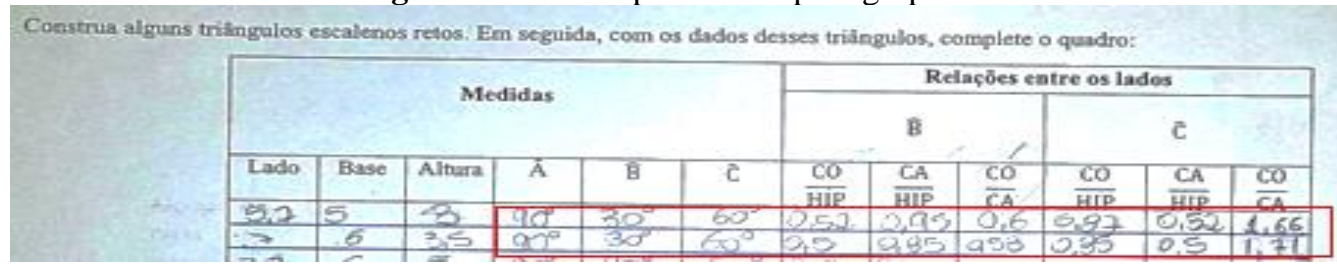

Fonte: Grupo G2 (2020).

$\mathrm{Na}$ terceira ficha referente à triângulos isósceles e a relações para o ângulo de $45^{\circ}$. Os alunos dos grupos G1, G2, G4 e G5 construíram todos os triângulos isósceles utilizando um ângulo de $90^{\circ}$, e anularam a coluna do ângulo Â como pode ser observado na Figura 2.

Figura 2 - Ficha 2 preenchida pelo grupo G5

\begin{tabular}{|c|c|c|c|c|c|c|c|c|c|c|c|c|c|c|}
\hline \multirow{2}{*}{\multicolumn{6}{|c|}{ Medidas }} & \multicolumn{9}{|c|}{ Relações entre os lados } \\
\hline & & & & & & \multicolumn{3}{|c|}{$\hat{A}$} & \multicolumn{3}{|c|}{ B } & \multicolumn{3}{|c|}{ C } \\
\hline $\begin{array}{l}\text { Lado } \\
(\mathrm{cm})\end{array}$ & $\begin{array}{l}\text { Base } \\
(\mathrm{cm})\end{array}$ & $\begin{array}{c}\text { Altura } \\
(\mathrm{cm})\end{array}$ & $\begin{array}{c}\hat{A} \\
\text { (graus) }\end{array}$ & $\begin{array}{c}\bar{B} \\
\text { (graus) }\end{array}$ & $\begin{array}{c}\bar{C} \\
\text { (graus) }\end{array}$ & $\frac{\mathrm{CO}}{\mathrm{HIP}}$ & $\frac{\mathrm{CA}}{\mathrm{HIP}}$ & $\frac{\mathrm{CO}}{\mathrm{CA}}$ & $\frac{\mathrm{CO}}{\mathrm{HIP}}$ & $\frac{\mathrm{CA}}{\mathrm{HIP}}$ & $\frac{\mathrm{CO}}{\mathrm{CA}}$ & $\frac{\mathrm{CO}}{\mathrm{HIP}}$ & $\frac{\mathrm{CA}}{\mathrm{HIP}}$ & $\frac{\mathrm{CO}}{\mathrm{CA}}$ \\
\hline $\begin{array}{l}15 \mathrm{~cm} \\
8,5 \mathrm{~cm}\end{array}$ & $\begin{array}{l}21 \mathrm{~cm} \\
6 \mathrm{~cm}\end{array}$ & $\begin{array}{l}15 \mathrm{~cm} \\
6 \mathrm{~cm}\end{array}$ & $\begin{array}{l}90^{\circ} \\
90^{\circ}\end{array}$ & $\begin{array}{l}49^{\circ} \\
45^{\circ}\end{array}$ & $\begin{array}{l}45^{\circ} \\
45^{\circ}\end{array}$ & $\ldots$ & - & - & $\left|\begin{array}{l}0,71 \mathrm{~cm} \\
0,70 \mathrm{~cm}\end{array}\right|$ & $\left|\begin{array}{l}0,71 \mathrm{~cm} \\
0,70 \mathrm{~cm}\end{array}\right|$ & $\begin{array}{l}1 \mathrm{~cm} \\
1 \mathrm{~cm}\end{array}$ & $\begin{array}{l}0,71 \mathrm{~cm} \\
0,70 \mathrm{~cm}\end{array} \mid$ & $\left|\begin{array}{l}0,71 \mathrm{~cm} \\
0,70 \mathrm{~cm}\end{array}\right|$ & $\begin{array}{l}1 \mathrm{~cm} \\
1 \mathrm{~cm}\end{array}$ \\
\hline
\end{tabular}

Fonte: Grupo G5 (2020). 
$\mathrm{Na}$ quarta e última ficha desejava-se que os acadêmicos percebessem que os valores encontrados em todas as atividades realizadas, referiam-se aos valores atribuídos aos ângulos notáveis $30^{\circ}$ (triângulo escaleno), $45^{\circ}$ (triângulo isósceles) e $60^{\circ}$ (triângulo equilátero), fazendo assim, a compreensão da relação entre os triângulos retângulos e os referidos ângulos. Usualmente, essa relação é passada aos alunos no Ensino Fundamental de maneira pronta e acabada, conforme pode ser observado no primeiro quadro da Figura 3. Já no segundo quadro, estão representados os valores dos ângulos notáveis em sua forma decimal, que foi a encontrada pelos participantes da pesquisa na realização de suas atividades:

Figura 3 - Tabela dos ângulos notáveis

\begin{tabular}{|c|c|c|c|}
\hline & $30^{\circ}$ & $\mathbf{4 5}^{\circ}$ & $\mathbf{6 0 ^ { \circ }}$ \\
\hline $\operatorname{sen}$ & $\frac{1}{2}$ & $\frac{\sqrt{2}}{2}$ & $\frac{\sqrt{3}}{2}$ \\
\hline $\cos$ & $\frac{\sqrt{3}}{2}$ & $\frac{\sqrt{2}}{2}$ & $\frac{1}{2}$ \\
\hline $\tan$ & $\frac{\sqrt{3}}{3}$ & 1 & $\sqrt{3}$ \\
\hline
\end{tabular}

\begin{tabular}{|l|c|c|c|}
\hline & $30^{\circ}$ & $45^{\circ}$ & $60^{\circ}$ \\
\hline Seno & 0,5 & 0,707 & 0,866 \\
\hline Cosseno & 0,866 & 0,707 & 0,5 \\
\hline Tangente & 0,577 & 1 & 1,73 \\
\hline
\end{tabular}

Fonte: Elaborado pelos autores (2020).

A Figura 4 apresenta os resultados apontados pelo G2 que revelou que os valores utilizados para preencher as respostas foram encontrados em suas tabelas durante a construção das fichas 1,2 e 3 , mostrando que a generalização pretendida foi atingida:

Figura 4 - Questão 1 da ficha 4 preenchida pelo grupo G2

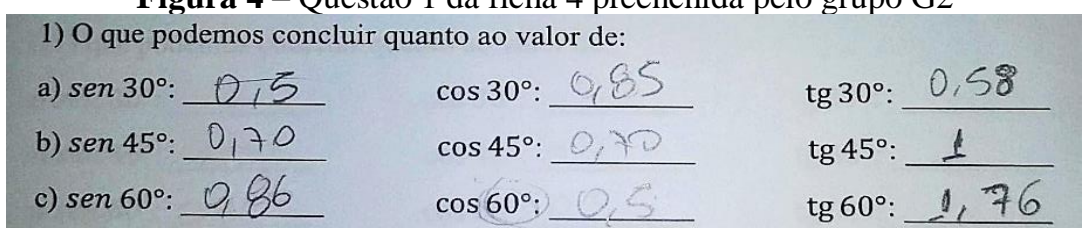

Fonte: Grupo G2 (2020).

Apenas o G1 não identificou está relação de modo imediato e necessitou do auxílio dos pesquisadores:
"P: Qual o valor do seno $60^{\circ}$ ?
A: raiz de 3 sobre 2
P: pega uma calculadora e vê quanto dá raiz de 3 dividido por 2
A: dá 0,86
P: olha na tabela de vocês do triângulo equilátero, o que vocês encontraram?
A: Nossa, deu o resultado que nós achamos aqui"

No momento do preenchimento desta última ficha, ficou nítido o papel de investigador que os acadêmicos assumiram durante a realização da atividade, pois se indagaram sobre o fato da matemática ser construída e não simplesmente estar "pronta e acabada", conforme relato do G5:

G: "ah, agora que eu fui entender a lógica da professora com esse exercício. Ela quer basicamente estabelecer as relações fundamentais da trigonometria de novo, a diferença é que você já sabe o que são os triângulos escalenos, isósceles, retângulo. Esse é o objetivo, aqueles ângulos fundamentais da trigonometria.

M: caramba!

G: "por isso que a gente tá se matando aqui, mas pensa quando Pitágoras, tipo, fez isso pela primeira vez?"

Segundo Ponte, Brocardo e Oliveira (2009) a Investigação Matemática proporciona ao investigador uma nova visão do conhecimento matemático por meio de um corpo de fatos e 
procedimentos que trabalham com quantidades, medidas e formas, de relações entre aqueles para um entendimento da matemática como uma ciência de padrões que se vai construindo por sucessivas tentativas, baseadas na observação e na experimentação, conforme ocorreu durante o desenvolvimento da atividade.

Para finalizar a implementação, foi realizada a discussão coletiva dos resultados obtidos com os participantes, e outro fato interessante foi percebido: os acadêmicos associaram a atividade realizada com o ciclo trigonométrico que eles haviam estudado durante a disciplina de Cálculo Diferencial e Integral I, este fato foi além do que havia sido planejado pelos pesquisadores, indo de encontro com o que é apontado por Ponte, Brocardo e Oliveira (2009, p. 17) de que "quando trabalhamos um problema, o nosso objetivo é, naturalmente resolvê-lo. No entanto, para além de resolver o problema proposto, podemos fazer outras descobertas que, em alguns casos, se revelam tão ou mais importantes que a solução do problema original", revelando que investigar constitui uma poderosa forma de construir conhecimento.

\section{CONSIDERAÇÕES FINAIS}

Seguindo as orientações e encaminhamentos da Investigação Matemática, realizamos uma atividade investigativa com o intuito de verificar como ocorre a construção das razões trigonométricas no triângulo retângulo. No desenvolvimento da atividade foi possível observar que os momentos constituintes de uma investigação, tais como, exploração e formulação de questões, formulação de conjecturas, testes e reformulações, justificação e avaliação das considerações encontradas por cada grupo, estiveram presentes durante todo o processo.

Ao compreenderem/construírem as relações existentes entre o triângulo retângulo e os ângulos notáveis durante a realização da atividade, os acadêmicos puderam perceber que, em específico na matemática, as coisas não estão prontas e acabadas. Além disso, a atividade ajudou a aguçar a curiosidade e promover o intuito de investigador nesses acadêmicos, que se mostraram interessados e motivados durante todo o processo. Diante dos resultados obtidos, concluímos que atividades investigativas podem se constituir como um auxílio ao professor para o processo de ensino-aprendizagem no que diz respeito a ressignificação de conceitos.

\section{REFERENCIAS}

BRASIL. Ministério da Educação. Parecer CNE/CES 1.362/2001. Diretrizes Curriculares Nacionais dos Cursos de Engenharia. Brasília: MEC/CNE, 25 de fevereiro de 2002.

BRASIL. Ministério da Educação. Resolução CNE/CES n² de 24 de abril de 2019. Institui as Diretrizes Curriculares Nacionais do Curso de Graduação em Engenharia. Diário Oficial da União, Brasília, 26 de abril de 2019, Seção 1, pp. 43 e 44.

FERREIRA, D. H. L.; BRUMATTI, R.N.M. Dificuldades em matemática em um curso de engenharia elétrica. Revista Horizontes, v.27, n.1, p. 51-60, 2009.

FERREIRA, L. B; TORRECILHA, N; MACHADO, S. H. S. A técnica de observação em estudos de administração. Encontro da ANPAD, v. 36, p. 1-15, 2012.

GIL, A. C. Como elaborar projetos de pesquisa. 4. ed. São Paulo: Atlas, 2002.

GODOY, E.; ALMEIDA, E. A evasão nos cursos de Engenharia e a sua relação com a Matemática: uma análise a partir do COBENGE. Educação Matemática Debate, v. 1, n. 3, p. 339-361, 2017. 
MAIA, É. J; ROSA, A. Z.; AFONSO, L. H. D. A matemática nos cursos de engenharia: uma análise das dificuldades apresentadas por acadêmicos ingressantes. In: XLVI Congresso Brasileiro de Educação em Engenharia (COBENGE) e $1^{\circ}$ Simpósio Internacional de Educação em Engenharia da ABENGE, 2018, Salvador - BA. Anais. 2018.

MANESTRINA, T.C.; MORAES, A.F. Alternativas para uma aprendizagem significativa em engenharia: curso de matemática básica. Revista de Ensino de Engenharia, v.30, n.1, p.

52-60, 2011.

NEVES, Miranilde Oliveira. A importância da investigação qualitativa no processo de formação continuada de professores: subsídios ao exercício da docência. Revista Fundamentos, v. 2, n. 1, 2015 .

PONTE, J. P.; BROCARDO, J; OLIVEIRA, H. Investigações matemáticas na sala de aula. 3 ed. ver. ampl, Belo Horizonte: Autêntica, 2013.

RIBEIRO, D. Conjectura. Dicio - Dicionário online de língua portuguesa. 2019. Disponível em: < https://www.dicio.com.br/conjectura/>. Acesso em jul. de 2020.

VILlELA, L. B.; CONDÉ, U. D.'O. C; NUNES, R. C. P. Disciplinas básicas do curso de Engenharia de Produção como possível causa de retenção e evasão. Anais Emepro, s/v, p. 1-11. 2018.

\section{TRIGONOMETRIC REASONS IN THE RECTANGLE TRIANGLE: REPORTING AN INVESTIGATIVE ACTIVITY IN ENGINEERING COURSES}

Abstract: The curriculum of the Engineering courses must give conditions to its graduates to acquire competences and skills related to mathematics and its applications. However, research carried out with undergraduate students of Engineering courses throughout Brazil, points to the gap and difficulty that these academics present in the specific subjects of the course that involve basic mathematics. Given this scenario, following the guidelines and guidelines of Mathematical Research, in this article, we present the report of the development of an investigative activity that aimed to verify how the students of Engineering courses identify (build) the trigonometric relations in the right triangle. To this end, 25 students enrolled in the 1 st semester of Engineering courses at an HEI participated in the research. The results revealed that by understanding / constructing the existing relationships between the right triangle and the notable angles during the activity, the academics were able to develop the intention of researchers. In addition, the activity helped to arouse curiosity in these academics who were interested and motivated throughout the process. We conclude that the Mathematical Investigation can be constituted as an aid to the teacher for the teaching-learning process of basic mathematics with regard to the reframing of concepts.

Keywords: Engineering Education. Basic math. Trigonometry. Mathematical research. 